Supporting Information for

\title{
Waterproof Phase Change Material with Facilely Incorporated Cellulose Nanocrystal/Poly(N-isopropylacrylamide) Network for All-weather Outdoor Thermal Energy Storage
}

Ling Zhou, Xue-feng Tao, Li-sheng Tang, Ming-Bo Yang, Wei Yang*

College of Polymer Science and Engineering, Sichuan University, State Key Laboratory of Polymer Materials Engineering, Chengdu, 610065 Sichuan, China

*To whom correspondence should be addressed. Email: weiyang@scu.edu.cn

Supporting information consists of 4 pages including 5 figures and 1 table. 


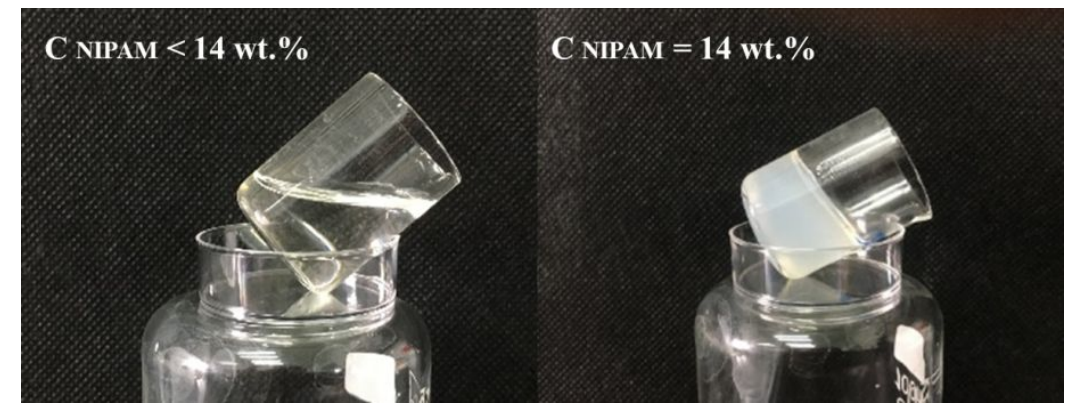

Figure S1. Photos of PNIPAM gel with $14 \mathrm{wt} . \%$ of NIPAM: the mixture containing $0.56 \mathrm{~g}$ of NIPAM, $0.048 \mathrm{~g}$ of MBA in $4 \mathrm{~g}$ of DMF can form gel within $30 \mathrm{~min}$ under UV-light.

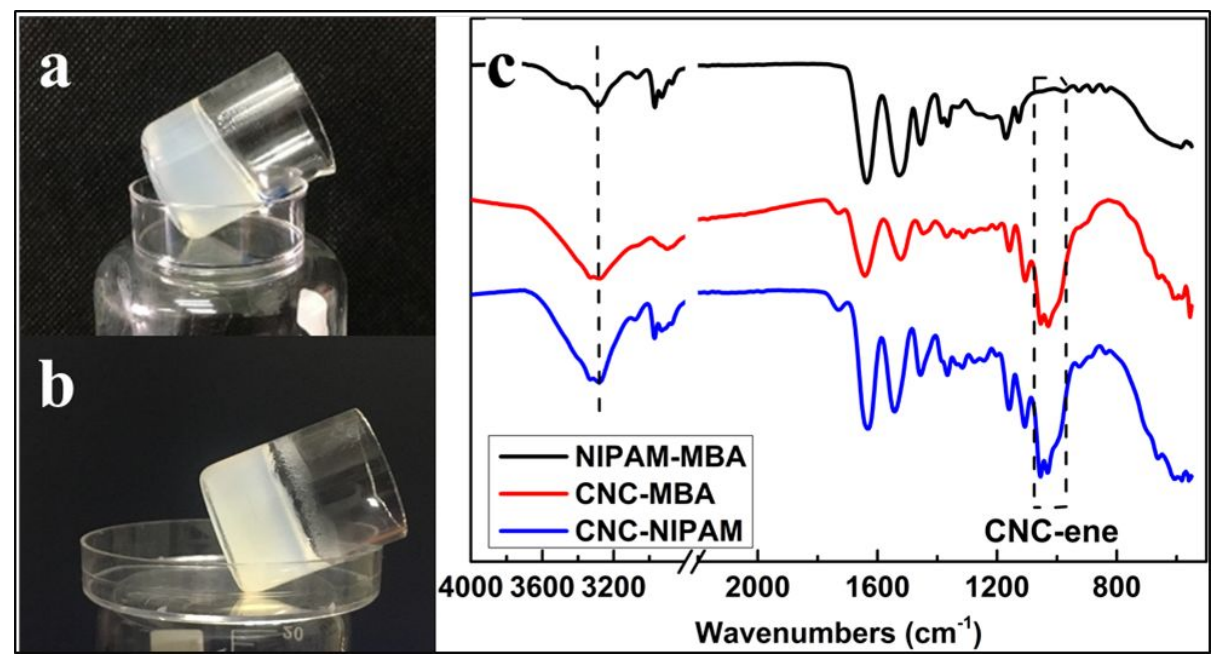

Figure S2. Photos of CNC-MBA gel (a), CNC-NIPAM gel (b) and FTIR spectra of NIPAM-MBA gel, CNC-MBA gel and CNC-NIPAM gel (c). The CNC-MBA gel was prepared by mixing $0.054 \mathrm{~g}$ of CNC-ene, $0.024 \mathrm{~g}$ of MBA and $0.012 \mathrm{~g}$ of DMPA in $4 \mathrm{~g}$ of DMF and irradiation crosslinking with UV-light for $30 \mathrm{~min}$. The CNC-NIPAM gel was prepared by mixing $0.054 \mathrm{~g}$ of CNC-ene, $0.56 \mathrm{~g}$ of NIPAM, and $0.024 \mathrm{~g}$ of DMPA in $4 \mathrm{~g}$ of DMF and irradiation crosslinking with UV-light for $30 \mathrm{~min}$. 


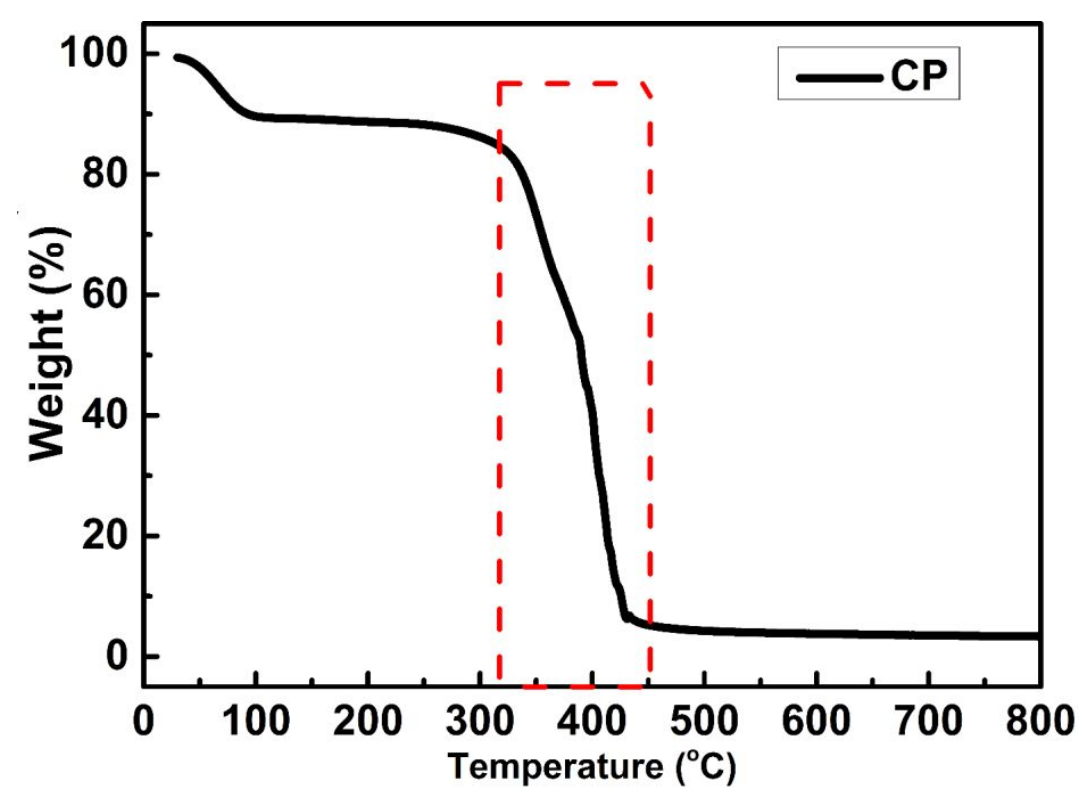

Figure S3. TGA curves of CNC/PNIPAM gel.

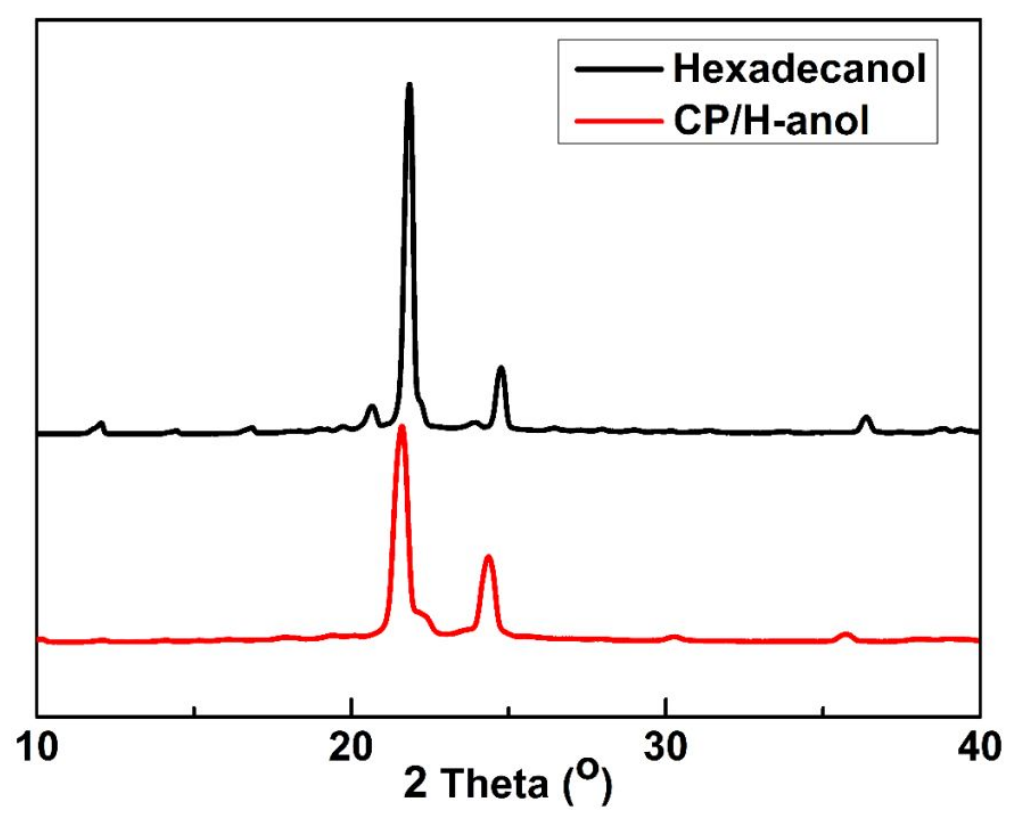

Figure S4. XRD patterns of pure hexadecanol and $\mathrm{CP} / \mathrm{H}-\mathrm{anol} \mathrm{PCM}$. Samples were analyzed on a DX-1000 diffractometer (XRD) using $\mathrm{Cu}$ Ka radiation $(\lambda=0.154 \mathrm{~nm})$ at a $40 \mathrm{~mA}$ current and a $40 \mathrm{kV}$ voltage. Samples were scanned at a scanning speed of $10^{\circ} / \mathrm{min}$ in the range of diffraction angle $2 \theta=5-50^{\circ}$. 
Table S1. Crystallization parameters of pure hexadecanol and CP/H-anol PCMs.

\begin{tabular}{cccccc}
\hline Sample & \multicolumn{2}{c}{$\mathbf{2 \theta}\left(^{\circ}\right)$} & \multicolumn{2}{c}{ FWHM $\left(^{\circ}\right)$} & Area $\beta / \gamma$ \\
\hline & Phase $\boldsymbol{\beta}$ & Phase $\boldsymbol{\gamma}$ & Phase $\boldsymbol{\beta}$ & Phase $\boldsymbol{\gamma}$ & \\
Hexadecanol & 21.85 & 24.78 & 0.306 & 0.285 & $100: 16.5$ \\
CP/H-anol & 21.62 & 24.38 & 0.486 & 0.392 & $100: 28.1$
\end{tabular}

Crystallization parameters were calculated by Jade 6 software.

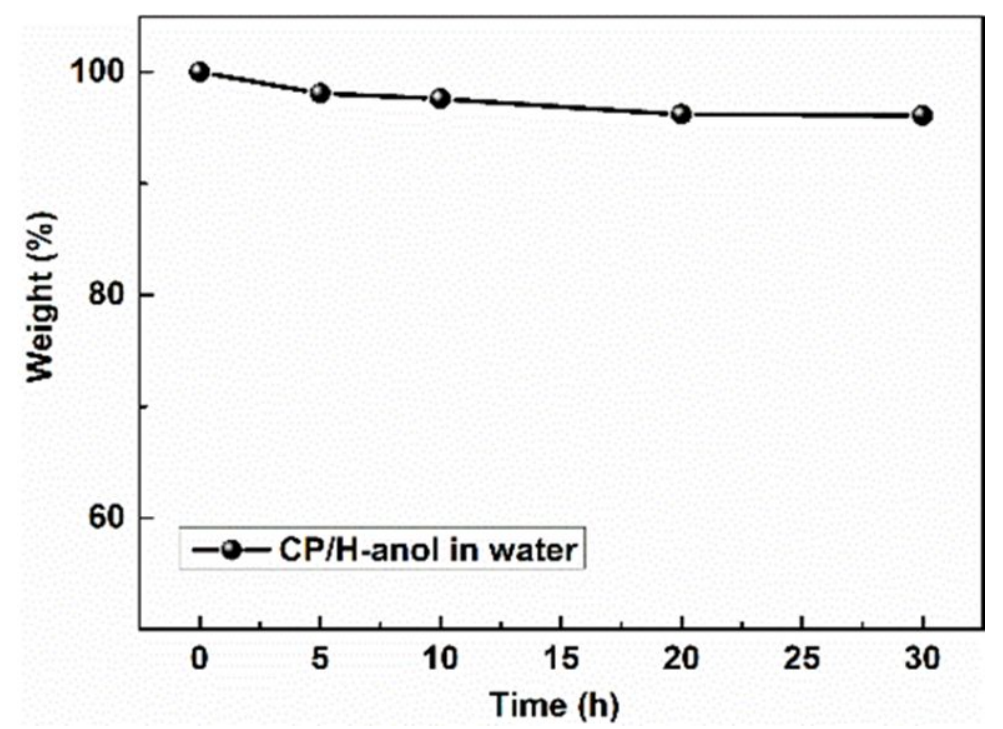

Figure S5. Weight percentage of $\mathrm{CP} / \mathrm{H}$-anol in $60^{\circ} \mathrm{C}$ water for $0,5,10,20$, and 30 hours. 